\title{
Taxonomía de las series de televisión españolas en la era digital (2000-2020)
}

\section{Taxonomy of Spanish television series in the digital era (2000-2020)}

\author{
Javier Mateos-Pérez; Rebeca Sirera-Blanco
}

Cómo citar este artículo:

Mateos-Pérez, Javier; Sirera-Blanco, Rebeca (2021). "Taxonomía de las series de televisión españolas en la era digital (2000-2020)". Profesional de la información, v. 30, n. 6, e300608.

https://doi.org/10.3145/epi.2021.nov.08

Artículo recibido el 20-07-2021

Aceptación definitiva: 17-09-2021

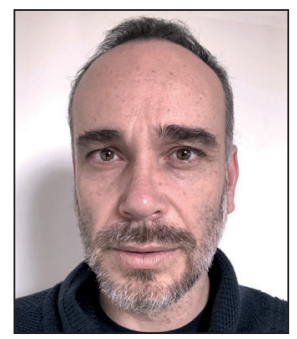

\author{
Javier Mateos-Pérez $\triangle$ \\ https://orcid.org/0000-0003-2056-8704 \\ Universidad Complutense de Madrid \\ Facultad de Ciencias de la Información \\ Dpto. de Periodismo y Comunicación Global \\ Av. Complutense, 3 \\ 28040 Madrid, España \\ jmateosperez@ucm.es
}

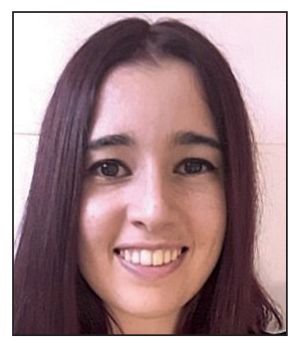

Rebeca Sirera-Blanco https://orcid.org/0000-0003-0288-173X

Universidad Complutense de Madrid Facultad de Ciencias de la Información Dpto. de Periodismo y Comunicación Global Av. Complutense, 3 28040 Madrid, España rsirera@ucm.es

\section{Resumen}

Se recopilan, cuantifican, clasifican y caracterizan las 545 series y miniseries de ficción de producción española, emitidas por los canales de televisión lineal, digital y las plataformas de vídeo bajo demanda, en el período 2000-2020. Se propone una metodología con un diseño mixto: cuantitativa y cualitativa. Se ha creado una base de datos que incluye los campos: año de estreno, formato, género, plataforma, canal, número de episodios y temporadas, duración y valoración. De esta manera se propone, por vez primera, una taxonomía que considera la caracterización completa del total de las ficciones seriadas españolas emitidas en España durante la era digital. Los resultados distinguen tres periodos por: el desarrollo de la ficción televisiva, la crisis económica de 2008, y la llegada de las plataformas de vídeo bajo demanda al país. Se concluye que las comedias han sido desbordadas por otros géneros mayoritarios, como los dramáticos o los policiales. La ficción de televisión se adapta a la nueva sociedad que las consume, retratando a través de temáticas novedosas sus debates sociales, sus miedos y sus aspiraciones. Se ha reducido su duración, mezclando unos géneros con otros y concediendo cada vez más presencia y protagonismo a personajes de mujeres en detrimento de los hombres.

\section{Palabras clave}

Series de televisión; Ficción televisiva; Televisión; Producción televisiva; Canales de televisión en abierto; Servicios de vídeo bajo demanda; Televisión autonómica; Televisión digital; Miniseries; Formatos televisivos; España.

\footnotetext{
Abstract

This article analyzes all fiction series and miniseries produced and broadcasted in Spain on linear and digital television channels as well as video-on-demand platforms in the period 2000-2020. The aim is to collect, quantify, classify, and characterize Spanish-produced television series. A methodology with a mixed, quantitative-qualitative design is proposed to quantify, classify, and categorize the 545 identified fictional works. The resulting database includes fields for the year of first broadcast, format, genre, platform, channel, number of episodes and seasons, duration, and rating. This taxonomy is the first to present a complete characterization of all fictional series produced and broadcasted in Spain during the digital era. Based on the results, three periods can be distinguished: the development of the series, the economic crisis of 2008, and the arrival of video-on-demand platforms in Spain. It is concluded that comedies have been overwhelmed by other major genres, such as dramas or police series. Television series are adapting to the new society that consumes them, portraying its social debates, fears, and aspirations through new themes while also reducing their length, mixing some genres with others, and with an increasing presence and prominence of female characters to the detriment of men.
} 


\section{Keywords}

Television series; Television fiction; Television; Television production; Free-to-air television channels; Video-on-demand services; Regional television; VoD; Digital television; Miniseries; Television formats; Spain.

Financiación

Este trabajo forma parte del proyecto de investigación: “Las series españolas de televisión del siglo XXI. Narrativas, estéticas, representaciones históricas y sociales”. Investigación financiada por el Programa de atracción al talento investigador de la Comunidad de Madrid. Ref. 2019-T1/SOC-12886.

\section{Introducción y estado de la cuestión}

La ficción televisiva se ha convertido en un fenómeno social, cultural y de entretenimiento en constante ascenso desde el inicio del siglo XXI en España (Álvarez-Monzoncillo; López-Villanueva, 1999; Torrado-Morales; Castelo-Blasco, 2005). Las series y miniseries de televisión han aumentado en número, importancia y peso dentro de la industria audiovisual en los últimos años. El valor de la industria de la ficción televisiva creció de 197 millones en 2017 a 404 millones en 2019 (Fernández, 2020), mientras que el incremento del número de producciones ha sido exponencial: de 38 series producidas en 2015, se ha pasado a 58 en 2018 (PWC, 2018, p. 5), y a 70 en 2020 (Mezzera, 2019).

Existen varias razones que explican este crecimiento. A las televisiones autonómicas y privadas ya existentes en España, en el presente siglo se unió la creación de dos nuevas cadenas (Cuatro y La sexta) y la llegada del apagón analógico de 2010, que propició la implantación de la televisión digital (TDT) y la aparición de nuevos canales temáticos. Otra razón fue la universalización del acceso a internet y la facilidad de las descargas, legales e ilegales, y la evolución en los aparatos tecnológicos, que modificaron las formas de consumo y ampliaron la demanda de contenidos audiovisuales de entretenimiento. Así, impulsadas por las tecnologías y los mercados globales, desembarcaron a partir de 2016 en España las plataformas VoD (video on demand). Este tipo de servicio OTT (over the top) supone una suscripción de bajo coste para el usuario a cambio de una cantidad ingente de contenidos audiovisuales cuyo producto estrella son las series de televisión. El informe Marco general de los medios en España 2021 (AIMC, 2021, p. 44) reveló que en 2016 el porcentaje de individuos con acceso a una plataforma VoD era del 1,2\%, mientras que cuatro años después, en 2020, ya superaba el 52,3\%, más de la mitad de la población española.

A las plataformas internacionales (Netflix, HBO, Amazon Prime Video), que comenzaron a producir ficción televisiva en nuestro país, se sumaron las españolas (como Filmin, Atresplayer o Playz), que también incluyeron en sus catálogos nuevas series producidas en el país. Este novedoso ecosistema de operadores motivó acuerdos y vínculos entre cadenas televisivas y servicios de streaming. Los principales grupos mediáticos en España entendieron la llegada de las plataformas VoD como una oportunidad para explotar los contenidos audiovisuales, lo que ha posibilitado una convivencia entre todos los medios televisivos. Esta estrategia ha permitido a la industria crear nuevos modelos de alianzas, multiplicar las posibilidades de creación de negocios y reconfigurar la producción de la ficción producida en España (Cascajosa-Virino, 2018a), lo que se ha traducido en un aumento de la producción y de la internacionalización de la ficción televisiva.

La influencia de la ficción televisiva ha traspasado el ámbito de la industria y ha ido calando en nuevos espacios sociales, hasta legitimarse culturalmente (Muñoz-Fernández, 2016). Tanto es así, que escritores, directores y actores y actrices reconocidos por sus obras cinematográficas y literarias participan ahora en proyectos televisivos.

En los últimos años se han multiplicado los contenidos y las informaciones sobre la ficción serial televisiva. Así, han proliferado los sitios web y los foros especializados, la edición de libros monográficos de divulgación y la creación de secciones, o incluso de publicaciones, en papel y digitales, consagradas a las series. Además, se han establecido certámenes y festivales para promocionar la industria e incluso, en el entorno académico, hoy abundan congresos, cursos, programas y masters universitarios en los que se enseña, se investiga y se debate acerca de la creación, la producción o el contenido de las series de televisión. Por ello no es de extrañar que incluso la investigación académica sobre las series y miniseries españolas haya incrementado su cantidad e importancia en el presente siglo (Mateos-Pérez, 2021).

Cabe señalar que las series españolas han traspasado fronteras y han logrado convertirse en fenómenos internacionales. 17 producciones españolas emitidas entre 2005 y 2017 se han adaptado en el extranjero (Diego; Grandío-Pérez, 2018); y, de las 20 series más vistas en Netflix en 2018, tres son españolas. La casa de papel es el título de habla no inglesa más consumido en la plataforma (PWC, 2018, pp. 36-37). Estos datos confirman la relevancia del sector español de la ficción televisiva en la industria audiovisual actual y lo que ello supone para la difusión de la cultura y la lengua hispana.

Hasta el momento, la ficción televisiva se ha estudiado, principalmente, desde las perspectivas de la producción, el contenido y la audiencia, por lo que no son frecuentes los trabajos que tratan de abarcar un conjunto amplio de títulos españoles. El Observatorio Iberoamericano de la Ficción Televisiva (Obitel) publica anualmente -desde 2007- un informe técnico que contabiliza producciones y explica las tendencias de la ficción televisiva emitida anualmente en cada país que lo integra. 
Existen otros trabajos académicos que reúnen una muestra significativa de series de televisión, pero no tienen un objetivo globalizador y apelan a diferentes enfoques. Se agrupan, por ejemplo, en función de los géneros a los que se adscriben, como la comedia o el policíaco. En relación con la primera, se han considerado 180 comedias emitidas en España, entre 1990 y 2018, que desarrollan una identidad española del género, pese a conservar rasgos definitorios de la comedia norteamericana (Gómez-Morales, 2020). También se han caracterizado las comedias familiares, emitidas entre 1990 y 2014 (Gómez-Rodríguez, 2017) para observar su evolución; y se han analizado hasta 46 series del subgénero familiar, emitidas por las cadenas generalistas, entre 1990 y 2010, para concluir que el modelo norteamericano se ha adaptado a la idiosincrasia española logrando un sello propio (Hidalgo-Marí, 2018).

En cuanto al género policíaco, se han estudiado 36 series emitidas por las televisiones españolas -desde 1990 hasta 2010- para concluir que los valores transmitidos por las cadenas privadas son más conservadores que en las públicas (Tous-Rovirosa, 2019), y que el uso de algunos recursos concretos, tanto narrativos como estéticos, la influencia de las producciones extranjeras y la hibridación entre géneros determinan la evolución del periodo (Tous-Rovirosa; Hidalgo-Marí; Morales-Morante, 2020).

Otra motivación que ha propiciado la recopilación de series de ficción ha sido la de analizar a los personajes que aparecen en ellas. De esta manera se ha analizado la representación de personajes inmigrantes (Marcos-Ramos; González-de-Garay; Portillo-Delgado, 2019; Marcos-Ramos; González-de-Garay, 2019) y de los grupos minoritarios (Marcos-Ramos; González-de-Garay; Arcila-Calderón, 2020) en las 24 series emitidas desde las cadenas generalistas durante 2016 y 2017, para reseñar su escasa presencia. La misma infrarrepresentación existe de las personas con diversidad funcional en las 47 producciones nacionales emitidas entre 2016 y 2018 (Palenzuela-Zanca; Marcos-Ramos; González-de-Garay, 2019); y en personajes no heterosexuales y con identidades de género no binarias en 21 series del período 2017-2018 (De-Caso-Bausela; González-de-Garay; Marcos-Ramos, 2020).

El estudio sobre la producción ha sido otro enfoque que ha requerido la compilación de una muestra extensa de ficciones televisivas como objeto de investigación. Como el trabajo que aúna 490 producciones -entre series, seriales, $T V$ movies y sketches- estrenados en las cadenas estatales entre 1990 y 2017, que demuestra que la ficción televisiva se ha afianzado desde el siglo pasado, con el incremento de estrenos y la mayor diversificación de géneros, formatos y contenidos, lo que da cuenta de la madurez y versatilidad alcanzada por el sistema (Lacalle; Sánchez-Ares, 2019).

A pesar de que todos estos trabajos cuantifican y caracterizan un buen número de ficciones televisivas españolas, lo hacen con el objeto de explorar un abordaje determinado, limitando su análisis a un período, dimensión o a un género concretos, y restringiendo la muestra únicamente a las producciones emitidas por emisores de señal nacional. Es decir, en estos análisis solo se ha considerado una muestra parcial de las series de televisión, por lo que siempre dejan fuera una cantidad relevante de producciones emitidas por otras televisiones, ya sean autonómicas, canales de pago, generalistas o plataformas VoD.

El presente trabajo trata de paliar esta carencia con un estudio pormenorizado que ofrece una taxonomía de todas las series de televisión españolas emitidas por el conjunto de los operadores televisivos -canales públicos y privados de televisión en abierto, de televisión de pago y plataformas VoD- de los primeros 20 años del siglo XXI. Por tanto, se busca responder a las siguientes preguntas de investigación:

¿Cuántas, cuáles y cómo son las series de ficción de producción española del siglo XXI?

¿Cuál es la evolución cuantitativa de la producción a lo largo del período?

¿Cuáles son los formatos, duraciones y géneros predominantes?

¿Cómo es la cuantificación de estrenos por televisiones (canales generalistas, autonómicos, digitales, de pago) y plataformas?

¿Cómo y cuál es la valoración que la audiencia realiza sobre ellas?

El objetivo es formular una propuesta de catálogo original, que considere una caracterización completa y que sirva como cartografía de las series de televisión de producción española en la era digital.

\section{Metodología}

La muestra de la investigación comprende las series de ficción televisiva. Se considera serie de ficción televisiva el producto audiovisual concebido para televisión y destinado al entretenimiento, compuesto por una narración de ficción seriada y articulada en dos o más capítulos, de determinada duración, que pueden desarrollarse en más de una temporada.

El propósito del estudio es recopilar, cuantificar, clasificar y caracterizar las series de televisión de producción española emitidas en el territorio nacional por las cadenas públicas y privadas de televisión en abierto, de alcance nacional o autonómico, por los canales de pago y por los servicios de vídeo bajo demanda. La etapa de estudio escogida abarca desde 2000 a 2020. Se consideran estos primeros 20 años del siglo XXI como el período de evolución televisiva en el que se ha 
producido la propagación global de la revolución digital y del género televisivo de las series, que ha acontecido de forma masiva, transnacional, y se ha convertido en un referente global del entretenimiento, apreciado por industria, público y crítica.

Como se ha dicho, el objetivo de este trabajo es componer una taxonomía de este formato de la ficción televisiva. Para ello se propone una metodología con un diseño mixto: cualitativa y cuantitativa. Este método se emplea considerando un conjunto de procesos sistemáticos, empíricos y críticos de investigación que implican la recolección y el análisis de datos cuantitativos y cualitativos, así como su integración y discusión conjunta para realizar inferencias y lograr un mayor entendimiento del fenómeno de estudio (Hernández-Sampieri; Fernández-Collado; Baptista-Lucio, 2010). Se trata de un trabajo de investigación de carácter:

- descriptivo: en tanto pretende exposición, registro, análisis e interpretación de la naturaleza, la composición o los procesos de los hechos bajo estudio (Tamayo-y-Tamayo, 1984);

- exploratorio: al articularlo a partir de la obtención de datos y de su interpretación;

- documental: se basa en la selección y búsqueda de información en elementos y materiales de naturaleza diversa (Baena, 2017).

El desarrollo de la investigación se ha llevado a cabo en cuatro fases. La fase 1 se ha sustentado en la elaboración de una base de datos relacional con 545 entradas y más de 14.000 registros que ha supuesto, a su vez, dos acciones. Por un lado, la búsqueda y recopilación de la totalidad de las series y, por otro lado, la caracterización de cada una a partir de información intensiva que considera las categorías: creación, dirección, producción, guionistas, formato, año, fecha y hora de estreno, plataformas de emisión, género, duración por capítulo, número de temporadas, número de episodios, resultados de audiencias, sinopsis, ambientación, temas, adaptaciones, premios, observaciones de producción, plan transmedia, presupuesto, target, cambios de programación, estrenos y puntuación en páginas especializadas (IMDb y Filmaffinity). La recopilación de toda esta información se realizó durante cuatro meses, de enero a abril de 2021 y está disponible en la web del proyecto de investigación:

https://seriestelevision.es/base-de-datos

La construcción de la base de datos relacional ha supuesto una exhaustiva labor de búsqueda y recogida de información, pues no hay ningún registro oficial que recoja cada una de las series y miniseries que se producen y estrenan en España, a diferencia de lo que ocurre, por ejemplo, con la producción editorial, musical o cinematográfica.

El primer paso fue averiguar y recopilar el total de series de ficción televisivas que se habían producido en el período de estudio. Tal y como se ha explicado, los anuarios de Obitel han sido una de las herramientas para llevar a cabo la recogida de información. Ofrecen un seguimiento anual de la ficción televisiva nacional y autonómica, y recogen todas las ficciones televisivas -series, miniseries y películas para televisión- exhibidas durante el año. Sin embargo, el primer anuario en papel está editado en 2007, y el primero digitalizado, data de 2011. Para completar el listado se recurrió a otras fuentes, como la base de datos del portal Filmaffinity, que cuenta con un buscador genérico que mezcla productos culturales de naturaleza diversa. La selección del género (series de televisión), país (España) y período (2000-2020) arrojó un total de 934 producciones. A este número se le fueron excluyendo las producciones de sketches, seriales y webseries, así como los títulos documentales y las producciones de no ficción. Esta aplicación recoge la mayor parte de las producciones, pero no la totalidad. No aparecen, por ejemplo, las series autonómicas que alcanzaron menor continuidad. Por este motivo, para completar la lista se consultaron los registros de las principales cadenas autonómicas españolas (Televisió de Catalunya, Euskal Telebista, Televisión de Galicia, Canal Sur), con el objeto de completar el listado considerando los diferentes repositorios de sus producciones de ficción.

Una vez que se completó el censo completo de las series, se emprendió la tarea de recogida de información relativa a las categorías establecidas en la base de datos. Para ello se recurrió a varias fuentes que, por momentos, ofrecían información contradictoria. Los anuarios de Obitel, desde 2011, IMDb y Filmaffinity proporcionaron detalles sobre la producción y sobre los creadores de numerosos títulos. Las webs de los canales y plataformas han sido útiles para contrastar y recabar información sobre la sinopsis o el número de episodios y temporadas. Como no todas las producciones están disponibles en la actualidad, para conseguir y/o cotejar la información se recurrió a la consulta hemerográfica de medios, tanto nacionales (El país, El mundo, eldiario.es, ABC, El español); como autonómicos (La voz de Galicia, Diari ARA, El nacional, Diario de Sevilla); y especializados (FórmulaTV, Vertele, PRNoticias o El televisero). Los periódicos diarios son un instrumento esencial para localizar noticias sobre las series y miniseries y permiten completar los datos más recónditos. Por último, en ocasiones, también se ha acudido a las webs personales de determinados creadores -guionistas, directores/as, etc.- para completar los datos.

La fase 2 ha consistido en la selección y la definición de categorías con el fin de determinar los niveles de análisis. Las diez categorías son:

1. Año de estreno: de la producción. 
2. Formato: se ha distinguido entre serie y miniserie. Entendemos por serie la narración de ficción, seriada, estructurada en episodios, y con elementos de continuidad en sus tramas que pueden ampliarse en más de una temporada. Se consideran miniseries las producciones emitidas en un máximo de cuatro episodios, que pueden ser películas producidas para televisión y contener historias basadas en hechos reales o en personajes populares.

3. Productora: con el fin de seguir unos criterios comunes, se ha priorizado la información de la base de datos IMDb.

4. Género: con el fin de solventar el problema de la hibridación de géneros, se ha delimitado el número de posibilidades a 7, priorizando el género más identificativo de cada serie. En caso de duda, la guía ha sido la categorización que proponen los portales Filmaffinity y FórmulaTV.

5. Plataforma: se diferencia entre televisión y plataforma de video bajo demanda.

6. Canal: pese a que algunas series se han emitido en distintos operadores, aquí se considera solo el canal de estreno. Para facilitar el análisis y exposición de los datos se ha decidido agrupar los canales en seis subcategorías:

- generalistas (La 1, La 2, Antena 3, Telecinco, La sexta, Cuatro);

- autonómicas (À punt, Aragón TV, Canal 9, Canal sur, CMMTV, ETB, IB3, Telemadrid, TV Canarias, TV3, TVG, V Televisión);

- canales de televisión de pago (Canalt, Comedy central, Paramount channel, Fox, TNT);

- temáticos (Neox, Disney channel, Clan, Atreseries);

- VoD (Atresplayer premium, Filmin, HBO, Movistar+, Netflix, Orange TV, Prime Video) y

- web (Flooxer, Playz, Canalplus.es).

7. Número de temporadas: entre series con una única temporada, dos temporadas, tres temporadas, cuatro temporadas y cinco temporadas o más.

8. Episodios: contabiliza el número total de capítulos.

9. Duración por episodio: se han creado subcategorías según los estándares: entre 20 y 30 minutos, entre 40 y 50 minutos y las de más de 60 minutos.

10. Valoración: calificación de las series por parte de los usuarios en las bases de datos IMDb y Filmaffinity.

La fase 3 ha consistido en la cuantificación y clasificación de los datos y en la realización de un estudio estadístico. Para analizar el banco de datos se ha seguido un procedimiento sistemático a partir de la ficha de análisis (tabla 1).

Por último, en la fase 4 se ha procedido a analizar el banco de datos aplicando un análisis del discurso con el que ofrecer una explicación a los datos estadísticos obtenidos. Esta fase de orientación cualitativa propone un trabajo de síntesis con el objeto de unir y relacionar los datos con el fin de identificar patrones y tendencias, y así combinar la presentación descriptiva de resultados con la interpretación crítica de los mismos.

\section{Resultados}

\subsection{Clasificación, caracterización, valoración y emisión de series españolas de ficción}

La relación entre los productos de ficción concebidos para televisión y los creados para servicios de vídeo bajo demanda en términos absolutos es muy desigual. Las series emitidas en canales de televisión tradicionales y digitales suponen el $89 \%$ del total, mientras que las ficciones estrenadas en los servicios VoD apenas alcanzan el $11 \%$. Sin embargo, la tendencia se ha revertido en el último lustro (gráfico 1). Desde la implantación en 2016 de las plataformas de VoD en nuestro país, la producción de series de ficción realizada por estos operadores ha destacado. Tanto es así que ya en 2020 los servicios de vídeo bajo demanda estrenan más series de ficción en España que los canales de televisión.
Tabla 1. Ficha de análisis

\begin{tabular}{|c|c|}
\hline Año de estreno & De 2000 a 2020 \\
\hline \multirow{2}{*}{ Formato } & Serie \\
\hline & Miniserie \\
\hline Productora/s & Nombre de la productora original \\
\hline \multirow{7}{*}{ Género } & Drama \\
\hline & Comedia \\
\hline & Thriller \\
\hline & Aventuras \\
\hline & Misterio \\
\hline & Ciencia ficción \\
\hline & Acción \\
\hline \multirow{2}{*}{ Plataforma } & Televisión \\
\hline & Vídeo bajo demanda \\
\hline \multirow{6}{*}{ Canal } & Generalistas \\
\hline & Autonómicas \\
\hline & Vídeo bajo demanda \\
\hline & Canales de televisión de pago \\
\hline & Temáticas \\
\hline & Web \\
\hline \multirow{5}{*}{ Número de temporadas } & 1 \\
\hline & 2 \\
\hline & 3 \\
\hline & 4 \\
\hline & 5 o más \\
\hline $\begin{array}{l}\text { Número de episodios por } \\
\text { temporada }\end{array}$ & Número de capítulos total por serie \\
\hline \multirow{3}{*}{ Duración por episodio } & $25-30 \mathrm{~min}$ \\
\hline & $40-50 \mathrm{~min}$ \\
\hline & Más de 60 min \\
\hline Puntuación & De 1 a 10 \\
\hline
\end{tabular}


Además de los cambios experimentados en el ecosistema audiovisual y de las transformaciones operadas en el consumo de la audiencia, otra de las razones que explica este cambio de tendencia es la apuesta de las cadenas generalistas por privilegiar sus propias plataformas VoD para el estreno de series de ficción. En Atresmedia, por ejemplo, de las 9 series de televisión estrenadas en 2020, 8 formaron parte del contenido exclusivo de su plataforma de pago Atresplayer Premium y tan solo el thriller Perdida (2020), se emitió en Antena 3.

No obstante, a lo largo de los veinte años analizados las cadenas de televisión lineal (nacionales y autonómicas) han emitido cuatro de cada cinco series estrenadas en España (gráfico 2).

Dentro de la televisión tradicional $A n$ tena 3 es la privada que mayor número de estrenos de series ha realizado, seguida de su competencia directa, Televisión Española y Telecinco. Estas tres televisiones destacan del resto de canales generalistas españoles de forma notoria. Las series de televisión no han sido, ni para Cuatro ni para La sex$t a$, una apuesta significativa en su estrategia de programación. Algo similar ocurre con los canales autonómicos, donde dos de ellos - Televisió de Catalunya (TV3) y Televisión de Galicia (TVG)-, sobresalen del resto de forma notable. De ellos se puede decir que son los canales regionales que mayor tradición de producción de series tienen. TV3, de hecho, ha estrenado series como Merlí (2015) o Polseres vermelles (2011), que se han acabado doblando al castellano y emitiendo tanto en España como en otros países.

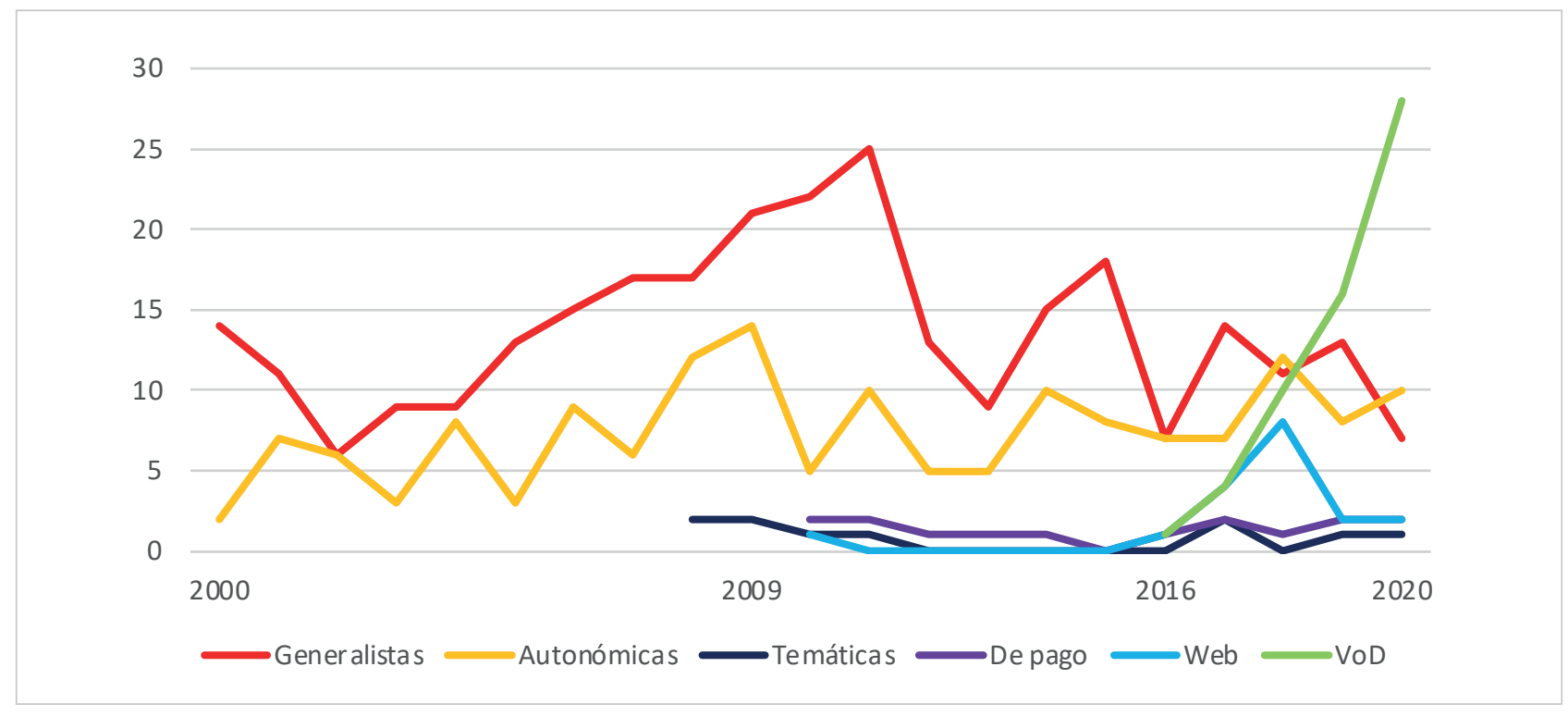

Gráfico 3. Evolución del número de series de las cadenas y plataformas VoD 
Canal+ y su proyecto de continuación financiado por Telefónica, \#0, es el canal de pago que más importancia ha otorgado a la producción y emisión de series, en línea con su estrategia de ofrecer una programación atractiva, propia y de calidad que justifique el pago de una cuota de suscripción al canal. En este sentido, a pesar de que producir series es una inversión costosa, se asume la inversión porque además de horas de contenidos audiovisuales originales aportan una imagen de marca que valoriza al canal.

Las plataformas de vídeo bajo demanda se incorporaron a la producción de ficciones televisivas nacionales en 2016. La que más producciones ha estrenado es Movistart, con un total de 22 series en tres años (tabla 2). Esta, siguiendo la estela de otras compañías como Netflix o $H B O$, ha basado el valor de su marca y su identidad apostando por la producción de ficciones televisivas (Cascajosa-Virino, 2018b). Sin embargo, Movistar+ no es el único grupo nacional que se ha incorporado a la producción de series nacionales. Desde que comenzara su estrategia en 2019, Atresplayer Premium ha estrenado nueve ficciones. Mientras que Movistar+ apuesta por un contenido basado en cuidados valores de producción y diversidad en géneros (Justo antes de Cristo, La zona, Vida perfecta), Atresmedia, que ya es la segunda en volumen de producción de series, recurre a títulos que nacen del fenómeno fan (Física o química: el reencuentro, By Ana Milán) y de contenido LGTBIQ+ (Veneno, \#Luimelia). Amazon prime video ha sido la última plataforma en unirse a la producción de ficción original. Actualmente, una de las fórmulas principales de este servicio es el recurso de preestrenar en exclusiva nuevas temporadas de series producidas originalmente en otras cadenas, como es el caso de Caronte (2020), La que se avecina (2007) o Señoras del (h)AMPA (2019), todas del grupo Mediaset.

Neox, el canal para el público joven del grupo Atresmedia, es el temático que más series ha estrenado (5) desde que naciera en 2008. Por su parte, su equivalente en RTVE, Playz, es la que más series ha producido. El proyecto se puso en marcha en 2017 y desde entonces han estrenado 16 series, mayoritariamente comedias o thrillers.
Tabla 2. Número de series estrenadas por televisiones, cadenas y plataformas (2000-2020)

\begin{tabular}{|c|c|c|}
\hline \multirow{6}{*}{ Generalistas } & Antena 3 & 100 \\
\hline & Cuatro & 16 \\
\hline & $\operatorname{La} 1$ & 82 \\
\hline & $\operatorname{La} 2$ & 13 \\
\hline & La sexta & 4 \\
\hline & Telecinco & 81 \\
\hline \multirow{12}{*}{ Autonómicas } & À Punt & 4 \\
\hline & Aragón TV & 2 \\
\hline & Canal 9 & 11 \\
\hline & Canal sur & 11 \\
\hline & Castilla-La Mancha Media TV & 1 \\
\hline & Euskal telebista & 13 \\
\hline & IB3 & 9 \\
\hline & Telemadrid & 6 \\
\hline & TV Canarias & 2 \\
\hline & Televisió de Catalunya & 50 \\
\hline & Televisión de Galicia & 47 \\
\hline & VTelevisión & 1 \\
\hline \multirow{6}{*}{ De pago } & $\# 0$ & 4 \\
\hline & Canal + & 4 \\
\hline & Comedy central & 2 \\
\hline & Fox & 1 \\
\hline & Paramount channel & 1 \\
\hline & TNT & 3 \\
\hline \multirow{4}{*}{ Temáticas } & Neox & 5 \\
\hline & Disney channel & 3 \\
\hline & Clan & 1 \\
\hline & Atreseries & 1 \\
\hline \multirow{3}{*}{ Web } & Canalplus.es & 1 \\
\hline & Flooxer & 1 \\
\hline & Playz & 16 \\
\hline \multirow{7}{*}{ Plataformas VoD } & Atresplayer premium & 9 \\
\hline & Filmin & 1 \\
\hline & HBO España & 8 \\
\hline & Movistar+ & 22 \\
\hline & Netflix España & 11 \\
\hline & Orange TV & 3 \\
\hline & Prime video & 5 \\
\hline
\end{tabular}

El estreno anual de las series de televisión durante este siglo parece dibujar una evolución caracterizada por tres períodos.

- El primero es el del desarrollo y la consolidación de las series como formato de primer orden en la televisión de España (2000-2009), que va desde el inicio del siglo hasta el año de la crisis financiera. En este tiempo, se advierte una emisión de series en constante aumento, que va desde las 11 series por año de 2003, a las 37 de 2009, siendo los canales generalistas los que más series estrenaron durante este período: 101 en total (gráfico 3).

- El segundo período (2010-2016), es el del padecimiento de la crisis, donde los efectos económicos negativos se hacen notar en la producción de series respecto a la evolución creciente experimentada por el género durante los años anteriores. Así, sufre un abrupto descenso a la mitad: de los 38 títulos al año de 2011, a los 19 del año siguiente, o incluso a los 15, de 2013.

- En el tercer período (2016-2020), con la aparición y el primer desarrollo de las plataformas de streaming, la emisión de series repunta partiendo de los 17 títulos de 2016, a casi triplicar la producción en 2020. Este aumento se produce gracias 


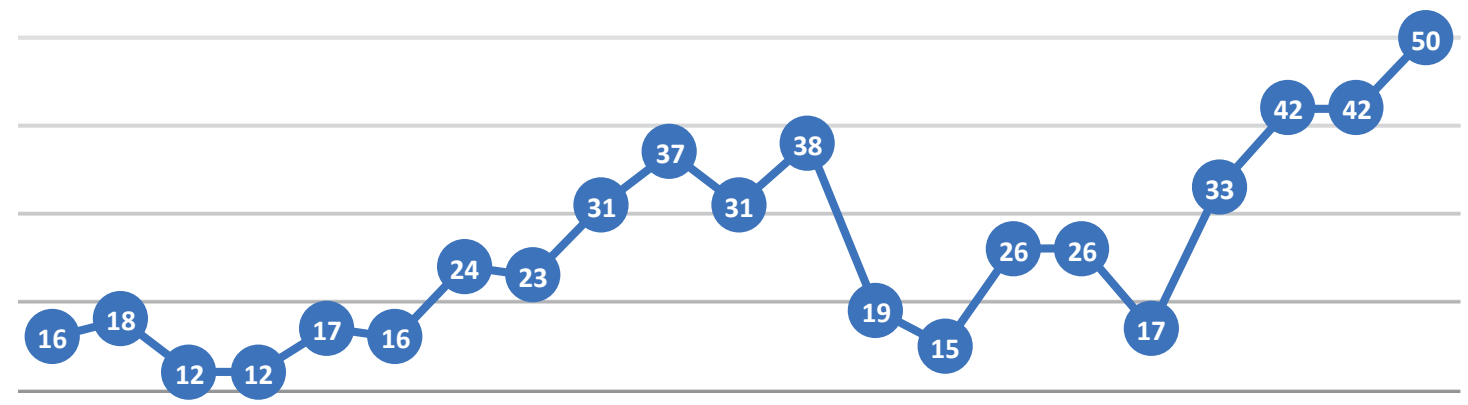

200020012002200320042005200620072008200920102011201220132014201520162017201820192020

Gráfico 4. Evolución del volumen de producción de series españolas por años (2000-2020)

al impulso que recibieron las series de ficción a partir de la implantación de las plataformas de video bajo demanda internacionales y españolas que, junto a la contribución de los canales de pago y los canales generalistas, consiguieron elevar la emisión del número de series hasta las 50 producciones (gráfico 4).

En cuanto al formato, se prioriza la serie $(80 \%)$ sobre la miniserie $(20 \%)$. Observando la evolución de ambas, se advierte que este formato funciona como un género más, que organiza ficciones a partir de historias, sucesos o personajes reales. En 2008 comenzó a aumentar la producción de miniseries llegando a equipararse en 2010 con el de las series, viviendo su apogeo al año siguiente (gráfico 5). Las historias de las miniseries emitidas en estos años narran sobre todo biopics sobre personajes españoles históricos o populares como Adolfo Suárez, el presidente (2010), o Raphael: una historia de superación (2010). También se narran historias basadas en hechos reales, como Vuelo IL8717 (2010), sobre el accidente de la aerolínea Spanair, o El caso Wanninkhof (2008), que cuenta la historia de Dolores Álvarez, condenada sin pruebas por el asesinato de Rocío Wanninkhof en 1999. La miniserie Felipe y Letizia (2010), que recreaba el noviazgo y matrimonio del heredero a la corona de España, fue la más vista, logrando una media de 4,7 millones de espectadores. Sin embargo, a partir de 2012, coincidiendo con la crisis económica, la producción de miniseries descendió hasta desaparecer de la televisión generalista en 2019. Las miniseries se han visto relegadas a los servicios de $\mathrm{VoD}$, que no dependen de una parrilla de programación y cuyo formato se adecúa mejor al consumo que se realiza en este tipo de plataformas.

Tres géneros han sido los predominantes en las series del siglo XXI. Casi el 90\% de las series se reparten entre dramas (42\%), comedias (33\%) y thrillers o policiales (15\%). Minoritarias han sido las series de acción y ciencia ficción (3\%), y residuales las producciones españolas que se han consagrado al género del terror o de las aventuras (2\%). Cabe destacar que durante el período de desarrollo - de 2003 a 2007- la comedia se impuso al drama (gráfico 6).

No obstante, una de las tendencias que se consolidan en los últimos años corresponde a la pluralidad de los géneros y a su intensa hibridación. El período de las plataformas (2016-2020) aglutina mayor número y variedad de series, por lo que, pese a que siguen predominando el drama y la comedia, cada vez es más complejo definir a la serie con un solo género predominante y existe una presencia más definida del resto de géneros. Esto se debe a la proliferación de operadores, plataformas y ofertas, lo que también ha producido una mayor diversificación de
Se establecen tres periodos en producción nacional de series en la era digital: 1) crecimiento de la producción (20002009); 2) efectos de la crisis económica (2010-2015); y 3) llegada de las plataformas VoD (2016-2020) 


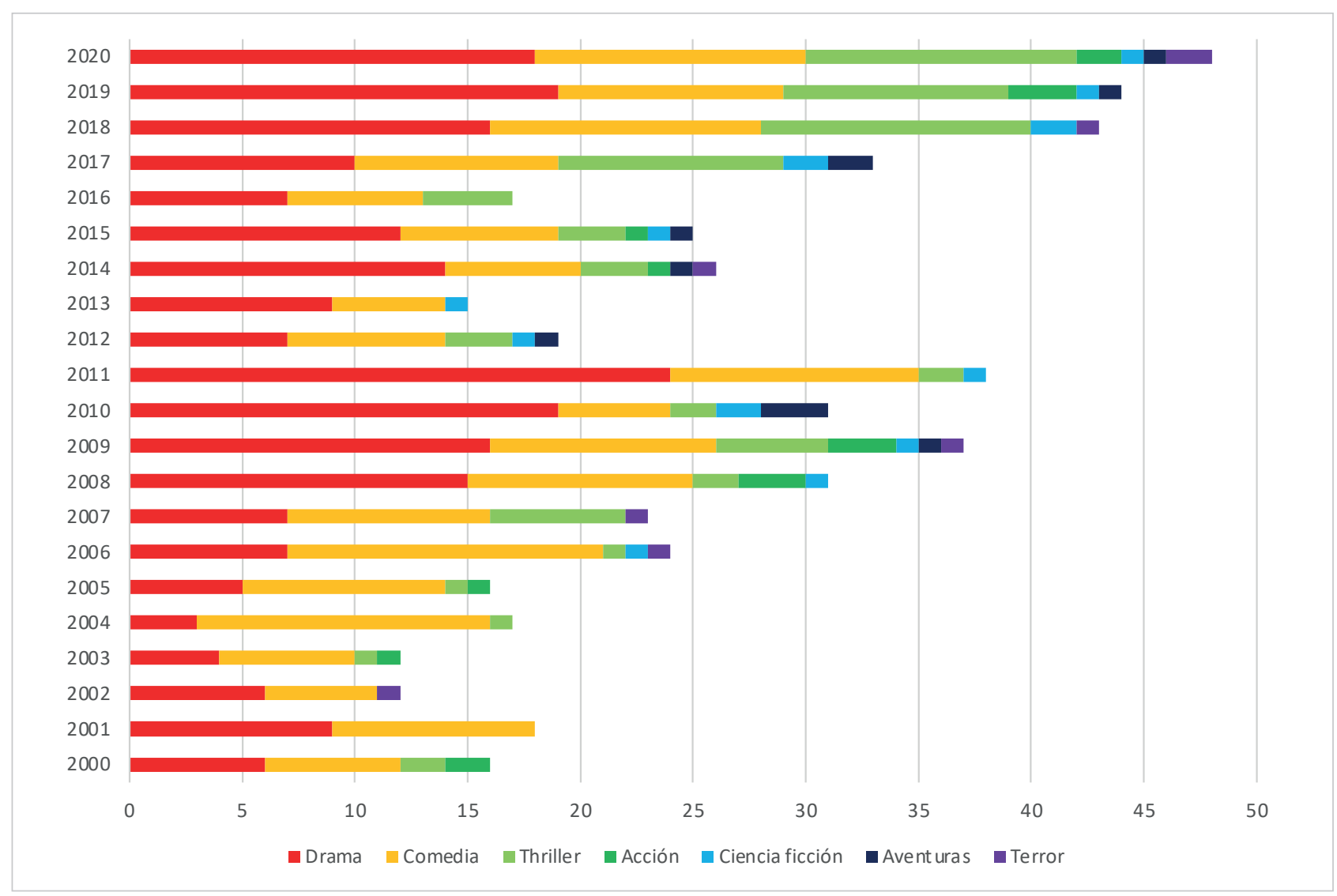

Gráfico 6. Géneros de las series de televisión por años

los públicos. Los canales en abierto emiten buscando a un público general y mayoritario. Sin embargo, las plataformas VoD o los canales digitales apuestan por públicos de nicho, con propuestas y temáticas más variadas y minoritarias, por lo que los géneros de las series son más numerosos, más heterogéneos, y hay una mayor oferta, lo que permite satisfacer a todo tipo de gustos y audiencias.

Con respecto a la duración, tan solo un tercio de las series españolas emitidas en los últimos veinte años ha conseguido renovar por una segunda temporada. En España las series tienen un promedio de 1,89 temporadas. Lo frecuente es que los proyectos de ficción serial televisiva en España concluyan con la primera (65\%) o con la segunda (18\%) entrega. Los proyectos más duraderos abarcan el $17 \%$ restante, significándose que hasta 28 series se han convertido en productos de larga continuidad, apoyadas por una audiencia fiel que las ha permitido permanecer en la pantalla 5 temporadas o

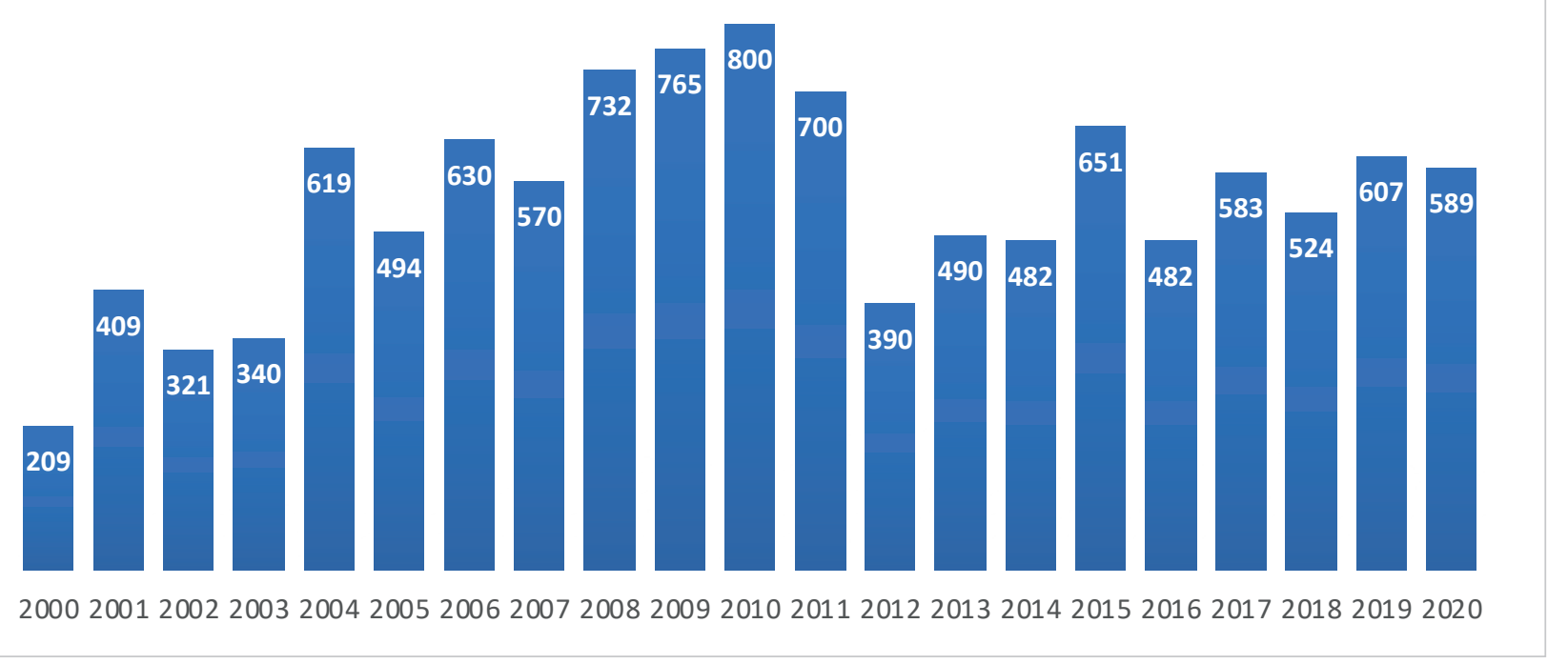


50

40

20

10

0

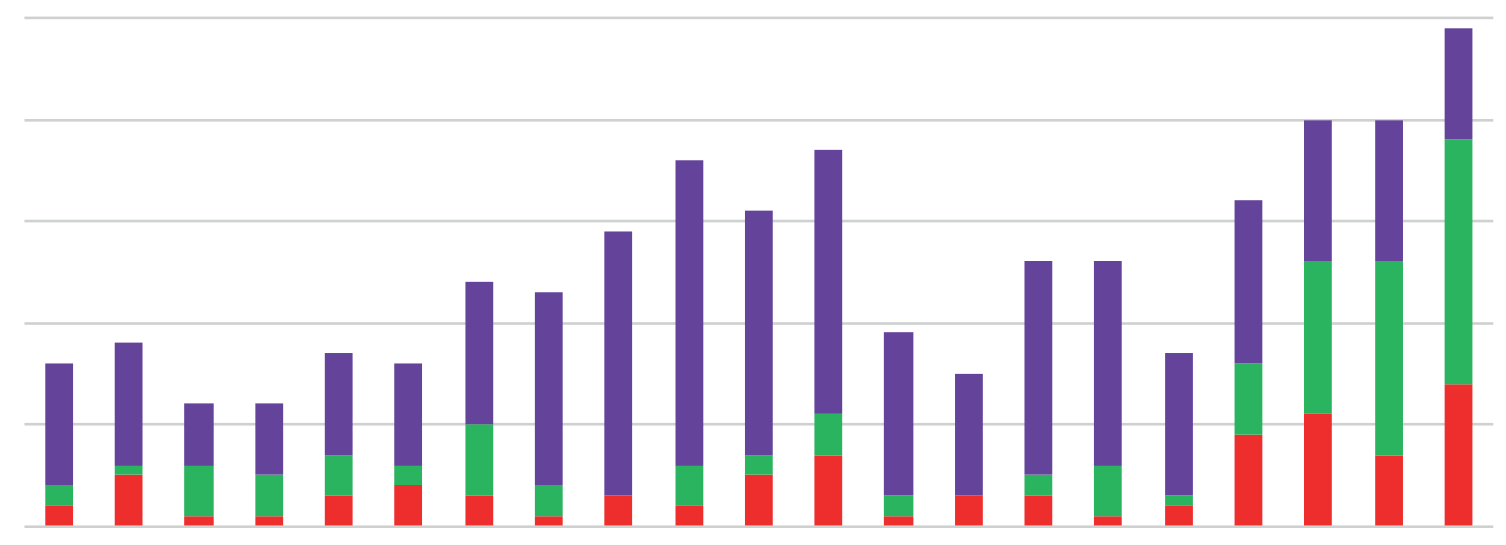

200020012002200320042005200620072008200920102011201220132014201520162017201820192020

— 25-30 minutos \$ Más de 60 minutos

Gráfico 8. Evolución de la duración de las series

más. La serie más longeva de la televisión en España es Libro de familia (2005), de TVG, que contó con 22 temporadas. Hospital central (2000), de Telecinco, y Cuéntame cómo pasó (2001), de La 1, suman 20 temporadas cada una, y se componen de más de 300 capítulos. También la televisión gallega cuenta con otra de las series más duraderas, Padre Casares (2008), que suma 16 temporadas.

Es necesario consignar que el género de la serie, en ocasiones, condiciona el número de episodios. Por ejemplo, cohabitan series cómicas de frecuencia diaria, como la sitcom Gym Toni (2014), cuyas temporadas constan de 85 capítulos, con otras series de corte dramático, compuestas por 8 capítulos por temporada, como Rabia (2015).

2020 es el año en el que más series y temporadas se han estrenado, sin embargo, la cantidad de episodios emitidos no supera a la de años anteriores (gráfico 7). Esto supone un cambio de tendencia que ha supuesto que:

- las producciones cuenten con menos episodios, pero con un presupuesto más elevado;

- el formato tradicional de sitcom, que se caracterizaba por contener más episodios con menos presupuesto, ha ido desvaneciéndose de las parrillas de programación.

Con respecto a la duración, la tendencia a lo largo de estas dos décadas han sido las series con capítulos de más de 60 minutos de duración (gráfico 8). Esto se debe principalmente a que la emisión de la serie de televisión se programaba encajándola -junto con los correspondientes segmentos de anuncios publicitarios- en los 120 minutos que abarca la franja del prime time en España. Coincidiendo con la llegada de los servicios de VoD, el formato predominante se redujo y pasó a ser el de 40 minutos. Las plataformas permiten al público elegir cuándo consumir los contenidos, por lo que proponen uniformar sus series al estándar dramático estadounidense de 40-45 minutos. Por último, hay que señalar que las series con una duración menor de 30 minutos están ganando presencia en los últimos cuatro años, independientemente de que su género se inscriba en el drama o en la comedia. En total, se ha contabilizado 678.107 minutos de ficción televisiva en España en estos últimos 20 años, lo que corresponde a 11.301 horas o lo que es lo mismo: 470 días completos de contenidos de ficción seriada.

Las series de menor duración son las preferidas para las plataformas web. Todas las series de esta categoría tienen una duración inferior a 30 minutos. Esto se debe a un nuevo paradigma en el consumo de ficción televisiva: que considera nuevos emisores -como las plataformas web-, nuevos públicos -como los jóvenes-, a los que se les supone un menor nivel de atención, y nuevos consumos -mediante diferentes pantallas-. Las producciones de 40-50 minutos son las más empleadas en las plataformas de VoD. El formato de duración más empleado lo encontramos en las cadenas generalistas. Casi la mitad del total de series contabilizadas tiene una duración mayor de 60 minutos y se han emitido en alguno de los seis canales generalistas.

En cuanto a las valoraciones, en este trabajo se incluye la evaluación de las series realizada por el público que recoge, por una parte: $I M D b$, la base de datos de referencia internacional (adquirida por Amazon en 1998), y Filmaffinity, la base de datos española más consultada, especializada en ofrecer información y valoración sobre producciones audiovisuales.
Las miniseries tuvieron su apogeo en los canales de televisión tradicionales en 2010. En los últimos años han encontrado su espacio en las plataformas de vídeo bajo demanda 
La valoración media de las series y miniseries españolas en los primeros 20 años del siglo XXI en Filmaffinity es de 5,02 puntos, mientras que en IMDb el promedio asciende a 6,46 puntos. En general, los usuarios de IMDb dan más puntuación a las producciones (tabla 3). Las únicas dos series que coinciden entre las diez primeras son Veneno (2020) y Merlí (2015). La mayoría de las producciones mejor valoradas de la lista de Filmaffinity pertenecen a cadenas generalistas, de pago o plataformas VoD (tabla 4). Sin embargo, en IMDb más de la mitad de las series mejor calificadas son de cadenas autonómicas. Una de las razones que explica este fenómeno es el número de usuarios que puntúan en los dos portales. La serie gallega Pepe O'Inglés (2006) recibió tan solo siete notas, mientras que la más valorada en Filmaffinity, Patria (2020), ha obtenido más de 14.000 valoraciones. Entendemos, por tanto, que las puntuaciones son relativas. Para valorar de forma más objetiva estos datos habría que considerar el número de usuarios que califican la producción. Otro factor a tener en cuenta es el año de estreno de las series. Las producciones que se valoran en el tiempo más próximo al estreno, obtienen mejor puntuación que las que se han emitido con años de diferencia.

Tabla 3. Top ten de series españolas mejor puntuadas en IMDb

\begin{tabular}{|l|l|l|c|c|}
\hline \multicolumn{1}{|c|}{ Serie } & Año & \multicolumn{2}{c|}{ Canal/plataforma } & Género \\
\hline Pepe O'Inglés & 2006 & TVG & Comedia \\
\hline Merlí & 2015 & TV3 & Drama \\
\hline Dalia, a modista & 2016 & TVG & Drama \\
\hline A estiba & 2019 & TVG & Thriller \\
\hline Veneno & 2020 & Atresplayerpremium & Drama \\
\hline Mai neva a ciutat & 2017 & IB3 & Drama \\
\hline Gran hotel & 2011 & Antena 3 & Drama \\
\hline Hospital real & 2015 & TVG & Drama \\
\hline El tiempo entre costuras & 2013 & Antena 3 & 8,5 \\
\hline Isabel & 2012 & La 1 & Drama \\
\hline
\end{tabular}

Tabla 4. Top ten de series españolas mejor puntuadas en Filmaffinity

\begin{tabular}{|l|l|l|c|c|}
\hline \multicolumn{1}{|c|}{ Serie } & Año & \multicolumn{1}{c|}{ Canal/plataforma } & Género \\
\hline Patria & 2020 & PBO & Drama \\
\hline Antidisturbios & 2020 & Movistar+ & Drama \\
\hline Matalobos & 2009 & TVG & Drama \\
\hline Fariña & 2018 & Antena 3 & Thriller \\
\hline El fin de la comedia & 2014 & Comedycentral & Comedia \\
\hline Merlí & 2015 & TV3 & Drama \\
\hline Veneno & 2020 & Atresplayer premium & Drama \\
\hline Crematorio & 2011 & Canal+ & 7,6 \\
\hline El día de mañana & 2018 & Movistar+ & Drama \\
\hline Conquistadores: Adventum & 2017 & $\# 0$ & Drama \\
\hline
\end{tabular}

\subsection{Etapas de la producción y sus características}

En los primeros 20 años del siglo XXI el desarrollo de la ficción televisiva ha fluctuado, ha experimentado cambios notables y, en general, ha crecido en forma apreciable. Factores como la crisis económica o la llegada de los servicios de vídeo bajo demanda han condicionado y han sido clave en la oscilación de la producción de series de televisión. Particularmente, se han formado tres períodos claros a lo largo de las dos décadas estudiadas, marcadas e influenciadas, precisamente, por estos dos factores.

Cada fase posee unas características particulares que definen diferentes modelos de ficción televisiva. La serie tipo durante el período de desarrollo, que corresponde la primera década del siglo XXI, posee un conjunto de atributos concretos: se trata de una producción emitida en una televisión generalista, cuyo género es la comedia, se compone de 2,5 temporadas y 39 episodios, y su duración rebasa los 60 minutos. La puntuación media de las series durante esta etapa llega a 4,4 en Filmaffinity, y a 6,05 en IMDb. Un modelo de ficción televisiva que se adapta a las citadas características de este periodo es La familia Mata (2007), una producción de Antena 3 con tres temporadas y que cuenta con 36 capítulos de 70 minutos de duración. Los usuarios de Filmaffinity la valoran por debajo del apro-

La proliferación del número de operadores en los últimos años ha dado lugar a nuevos modelos de negocio entre los canales tradiciones y las plataformas 
bado, con un 3,8, igual que los de $I M D b$, con un 4,8. Se trata de una comedia familiar en la que una joven pareja se ve obligada a convivir con la familia de ella porque su padre ha invertido el dinero de la futura casa del matrimonio y no tienen adonde ir. En la casa se concita una multitud: la pareja, los padres de ella, la tía excéntrica, el abuelo cascarrabias y el cuñado divorciado, que convive con sus dos hijos. La convivencia y las relaciones familiares son el eje central de la trama y uno de los principales temas asociados a las series de producción española del período.

Si atendemos a las series de éxito de este período con una temática similar, podemos destacar Aquí no hay quien viva (2003), con una audiencia media de 6 millones de espectadores (33,8\% de share) durante sus 5 temporadas; o Los Serrano (2003), ficción emitida en 15 países y adaptada en otros seis. Ambas fueron galardonadas con un Premio Ondas y trataban temas como las relaciones familiares y la convivencia. Además, el fenómeno fan que generó Los Serrano catapultó la carrera musical de uno de los actores, Fran Perea, y provocó la formación del grupo musical SJK compuesto por los adolescentes de la serie.

La segunda etapa, que abarca desde 2010 a 2015, comparte características con el período anterior, solo que en este caso el modelo resultante de serie está lastrado por la crisis, que reduce la producción de forma patente. Una diferencia entre ambos períodos se encuentra en la reducción del número de temporadas y capítulos. La serie promedio de este ciclo no llega a renovar por una segunda temporada (se mantiene en 1,9) y los capítulos descienden a 29. La calificación media de las series de este periodo es de 4,9 en Filmaffinity, y de 6,5 en IMDb. La ficción televisiva representativa de este lapso es Chiringuito de Pepe, emitida por Telecinco en 2014. Se trata de una comedia, de dos temporadas, con 29 capítulos de 75 minutos de duración. En Filmaffinity suspende con un 4,3, y en IMDb aprueba con un 6,3. La ficción tiene lugar en Peñíscola y comienza cuando Sergi, un prestigioso chef premiado con Estrellas Michelin descubre que Pepe, propietario de un chiringuito de playa sin mucho éxito, es su verdadero padre. Sergi trata de ayudarle con el negocio, aunque para ello tenga que adaptarse a un estilo de cocina diferente y a lidiar con sus nuevos compañeros. En este período también podemos destacar Allí Abajo (2015), inspirada en la popular película Ocho apellidos vascos, donde la adaptación a un nuevo medio, los estereotipos territoriales, las relaciones familiares y los choques culturales son el eje central de la trama. En sus 5 temporadas reunió a una media de 3 millones de espectadores (18,2\% de share).

La fase final comprende el último lustro del tiempo de estudio, de 2016 a 2020. En esta etapa aparecen y progresan las plataformas de vídeo bajo demanda en el panorama televisivo nacional. Los datos de la evolución del volumen de producción de ficción televisiva en los servicios de streaming, respecto de las televisiones lineales y de cable, avanzan un cambio de tendencia que sugiere que los productos de ficción se consumen cada vez más y de forma principal en plataformas VoD. Podemos observar un cambio en la tendencia de la producción de ficción, ya que durante estos 4 últimos años se estrenan más series en plataformas VoD que en televisión lineal, aunque los valores son muy ajustados. El género mayoritario vira de la comedia hacia el drama. La serie tipo de este período mantiene una duración superior a los 60 minutos por capítulo -pese a que se atisba un cambio de tendencia, reduciendo los tiempos en cada episodio-, produce una sola temporada (1,2), y 12 capítulos. Las valoraciones realizadas por internautas mejoran. Por fin aprueban las ficciones en Filmaffinity, con un 5,5 y los de IMDb mantienen el 6,3. Caronte (2020) es la serie que mejor ilustra este período. Se trata de un drama de una única temporada de 13 episodios de 60 minutos de duración estrenado en Prime video. Además, con este caso se ilustran los nuevos modelos de negocio en los que las plataformas digitales y los canales tradicionales convergen para preestrenar producciones en exclusiva antes de ser emitidas en abierto. En el caso de Caronte, inicialmente se iba a emitir en Telecinco, pero tras un año de su estreno en Prime video, Cuatro programó la serie en su parrilla. Otros modelos de este período han sido Las chicas del cable (2017), la primera producción de Netflix España, que cuenta con 5 temporadas y adaptaciones en cinco países o Antidisturbios (2020) un policíaco que se pega a la crónica actual.

Este último estadio marca un evidente cambio en el paradigma. En 2020 las plataformas de vídeo bajo demanda, tanto internacionales como nacionales, han emitido más series en conjunto que todos los canales de televisión. Este cambio no solo determina cómo consumimos las series, también nos muestra cómo son esas series. Los procesos de escritura y producción de las ficciones se adaptan a las nuevas pantallas y a las demandas del público considerando incluso a la audiencia de forma más heterogénea y de nicho.

\section{Conclusiones}

Los resultados muestran una clara tendencia de protagonismo de las series de ficción en las plataformas VoD. La consecuencia más inmediata es que las series españolas se estrenan en todo el mundo gracias a servicios como Netflix o $H B O$. Esto ha revolucionado la producción de la ficción. Las comedias han sido desbordadas por otros géneros mayoritarios, como los dramáticos o los policiales, que se erigen como los géneros en boga. Parece que esa comedia blanca, usualmente protagonizada por una familia y dirigida a audiencias de todas las edades, que fue célebre durante el origen, con series como Médico de familia (1995) o Los Serrano (2003), con numerosas temporadas y más de cien capítulos y que marcó los primeros 15 años de siglo, ha caducado. Por otra parte, también se advierte la escasez del formato sitcom en las plataformas de VoD. Además, el número de episodios y la duración de estos también se han alterado. Las series de ficción han menguado tanto la duración

Las series españolas se estrenan en todo el mundo gracias a servicios como Netflix o $H B O$ 
como el número de los episodios por temporada, pero, a cambio, los dotan con un presupuesto mayor. Los estándares de producción son cada vez más ambiciosos y necesarios para pugnar en un mercado cada vez más competitivo. Por ejemplo, se estima que el coste medio de un capítulo de una hora de las series norteamericanas producidas por plataformas de VoD se sitúa entre los 5 y los 7 millones de dólares (Ryan; Littleton, 2017), mientras que una temporada completa de La casa de papel tiene un costo aproximado de 4 millones de euros (Álvarez-Albalá, 2020).

Otra particularidad que se advierte a la hora de estudiar la evolución de las series en España es la presencia de la miniserie. Hemos entendido por miniserie los relatos seriados de corta duración cuya producción se asemeja al telefilme y cuya narración:

- se inspira en acontecimientos reales y noticiosos;

- se basa en relatos literarios (La memoria del agua, 2012; La duquesa, 2010; Operación Malaya, 2011) de probado éxito comercial;

- o en la vida de personajes históricos y/o populares;

- se estructuran a partir de películas de cine que se adaptan para televisión y transmutan en series al ser emitidas en varias entregas (El abuelo, 2000; La Mari, 2003; Rhesus, 2011).

En cualquier caso, las series están aproximando su duración cada vez más a las miniseries, incluso en ocasiones se utiliza este concepto para nombrar a series de corta duración y escasos capítulos, que están pensados para una única temporada. Es por esto por lo que aquí se considera miniserie como un género más, caracterizado por su inspiración en las temáticas reales más que por el formato que emplea.

La proliferación de la oferta y la aparición de nuevos emisores ha posibilitado nuevos modos de consumir ficción, lo que a su vez ha traído consigo la diversificación de las audiencias. En 2015 se contabilizan 10 cadenas de televisión que estrenan series. En 2020, los operadores que estrenaron ficciones televisivas se duplicaron. Mientras que la tendencia en la primera década consistía en crear ficciones dirigidas a un público generalista para tratar de convocar a la mayor audiencia posible, con la incorporación, primero, de las cadenas temáticas (2008) y la llegada posterior de las plataformas VoD (2016), la intención parece ahora haber variado y apunta a capturar a públicos más concretos. Como evidencia se comprueba que algunos géneros, tradicionalmente minoritarios en las producciones españolas de ficción televisiva, están ganando presencia. Los operadores televisivos buscan con ello diferenciarse definiendo una imagen que se distingue por el rango de público al que van dirigidos sus contenidos. Un ejemplo de ello es la plataforma Atresplayer premium, que orienta su contenido de ficción y entretenimiento a las redes sociales, el público joven y el colectivo LGTBIQ+. Por su parte, la plataforma Movistar+ ofrece series con temas actuales o novedosos y se dirigen a un público más adulto y exigente en cuanto a los estándares de producción y calidad de las series. Son producciones que tratan de imitar el modelo estadounidense en lo referido a estética y narrativa. Las series están dirigidas a un consumidor habitual de ficción televisiva, ya sea de comedia, drama, aventura o thriller, los géneros primordiales en las ficciones de esta plataforma.

Son reveladores los nuevos modelos de negocio aparecidos a raíz de la implantación de las plataformas de vídeo bajo demanda. Desde 2016 productoras y cadenas televisivas llegan a acuerdos de emisión de sus productos con el fin de amortizar títulos. Un ejemplo lo encontramos en Mediaset España. Series como Madres (2020), El pueblo (2019) o Señoras del (h)AMPA (2019) se estrenan antes en Prime video que en Cuatro o Telecinco. La demora del estreno en abierto puede prolongarse hasta un año, como ha sido el caso de la segunda temporada de Madres. Atresmedia, sin embargo, ha optado por el modelo inverso. Preestrenan las ficciones en Atresplayer premium, emiten en Antena 3 y, a continuación, rentabilizan esos títulos en otras plataformas de vídeo bajo demanda. Algunos casos han sido Toy boy (2019) o La casa de papel (2017). Títulos que no fueron exitosos en su estreno en abierto, pero después se convirtieron en un fenómeno en las plataformas.

Estas estrategias han sido menos frecuentes en las televisiones públicas. Pese a que algunas producciones como La otra mirada (2019) o Estoy vivo (2017) están disponibles en plataformas de vídeo bajo demanda, RTVE solo ha preestrenado Inés del alma mía (2020) en Prime video. Merlí (2015) o Polseres vermelles (2011), ambas de TV3, han traspasado fronteras y han conseguido destacar en regiones de Europa y América.

Los datos analizados sobre las ficciones estrenadas en España durante las últimas dos décadas señalan un cambio de paradigma. Los grupos mediáticos están apostando por crear ficción para ser consumida en sus propias plataformas. En 2020 ninguna de las series de ficción nacionales estrenadas por los canales en abierto ha superado el millón y medio de espectadores, ni el $10 \%$ de share. Los cambios producidos en el ecosistema audiovisual, en los consumos televisivos, en la industria y en la misma sociedad española parecen tener una correlación directa sobre las series de televisión. Éstas están mutando y se adaptan a la nueva sociedad que las consume, retratando, a través de propuestas singulares, sus miedos, sus debates sociales y sus aspiraciones, también reduciendo su duración y mezclando y privilegiando unos géneros sobre otros, proponiendo nuevas temáticas y concediendo cada vez más presencia y protagonismo a personajes mujeres en detrimento de los hombres. La década de los 20 presagia ficciones televisivas cada vez con menor duración, basadas en temáticas actuales y polémicas, que emplean géneros cruzados, metaficción y referencias a la realidad local en escenarios singulares. Aunque no se prevé que el género de ficción televisiva descienda en su consumo en los próximos años, se aventura una evolución en la industria con más incógnitas que certezas ante un escenario internacional cada vez más cambiante. 


\section{Referencias}

Álvarez-Albalá, Carolina (2020). “España gasta más en series que en cine: presupuestos de 10 millones”. El independiente, 6 junio.

https://www.elindependiente.com/series-y-television/2020/06/06/espana-gasta-mas-en-series-que-en-cinepresupuestos-de-10-millones

Álvarez-Monzoncillo, José-María; López-Villanueva, Javier (1999). “La producción de ficción en España: un cambio de ciclo". Zer, v. 4, n. 7, pp. 65-86.

https://ojs.ehu.eus/index.php/Zer/article/view/1

AIMC (2021). Marco general de los medios en España 2021. Asociación para la Investigación de Medios de Comunicación. https://www.aimc.es/otros-estudios-trabajos/marco-general

Baena, Guillermina (2017). Metodología de la investigación. México: Grupo Editorial Patria. ISBN: 9786077440031

Cascajosa-Virino, Concepción (2018a). “De la televisión de pago al vídeo bajo demanda. Análisis de la primera temporada de la estrategia de producción original de ficción de Movistar+". Fonseca, n. 17, pp. 57-74.

https://doi.org/10.14201/fjc2018175774

Cascajosa-Virino, Concepción (2018b). "Las series de televisión españolas ante la llegada de los servicios VoD (20152017)". El profesional de la información, v. 27, n. 6, pp. 1303-1312.

https://doi.org/10.3145/epi.2018.nov.13

De-Caso-Bausela, Elisa; González-de-Garay, Beatriz; Marcos-Ramos, María (2020). “Representación de género en las series generalistas de televisión españolas emitidas en prime time (2017-2018)". El profesional de la información, v. 29, n. 2, e290208.

https://doi.org/10.3145/epi.2020.mar.08

Diego, Patricia; Grandío-Pérez, María-del-Mar (2018). “El asentamiento de la ficción seriada española en el extranjero (2005-2017). El caso de la adaptación norteamericana de Los misterios de Laura desde el punto de vista de sus creadores". Revista latina de comunicación social, v. 73, pp. 828-844.

https://doi.org/10.4185/RLCS-2018-1284

Fernández, Rosa (2020). "Valor de la industria de las series y lucro cesante por efecto de la piratería en España (20172019)". Statista, 20 octubre.

https://es.statista.com/estadisticas/480715/pirateria-lucro-cesante-valor-de-la-industria-de-la-television-espana

Gómez-Morales, Beatriz (2020). “La definición de una narrativa propia. La comedia televisiva española (1990-2018)”. Cuadernos.info, n. 45, pp. 342-366.

https://doi.org/10.7764/cdi.46.1804

Gómez-Rodríguez, Gema-María (2017). “Comedia a la española. La evolución del género en televisión (1990-2014)”. Comunicación y medios, n. 35, pp. 36-51.

https://comunicacionymedios.uchile.cl/index.php/RCM/article/view/45156

Hernández-Sampieri, Roberto; Fernández-Collado, Carlos; Baptista-Lucio, Pilar (2010). Metodología de la investigación. México: McGraw Hill. ISBN: 9781456223960

Hidalgo-Marí, Tatiana (2018). "La comedia familiar española desde la apertura del mercado televisivo hasta el apagón analógico: formatos, audiencias y producción (1990-2010)". Communication \& society, v. 31, n. 2, pp. 39-50.

http://rua.ua.es/dspace/handle/10045/74750

Lacalle, Charo; Sánchez-Ares, Mariluz (2019). "Producción de ficción televisiva española a partir de la desregulación: entre la atomización de las empresas y la concentración vertical". El profesional de la información, v. 28, n. 1, e280110. https://doi.org/10.3145/epi.2019.ene.10

Marcos-Ramos, María; González-de-Garay, Beatriz (2019). "The psychosocial portrayals of immigrants in Spanish prime time television fiction (2016-2017)". Communication \& society, v. 32, n. 4.

https://doi.org/10.15581/003.32.4.1-15

Marcos-Ramos, María; González-de-Garay, Beatriz; Arcila-Calderón, Carlos (2020). "Grupos minoritarios en la ficción televisiva española: análisis de contenido y percepciones ciudadanas para la creación de un índice de diversidad". Cuadernos.info, n. 46, pp. 307-341.

https://doi.org/10.7764/cdi.46.1739

Marcos-Ramos, María; González-de-Garay, Beatriz; Portillo-Delgado, Carla (2019). "La representación de la inmigración en la ficción serial española contemporánea de prime time”. Revista latina de comunicación social, v. 74, n. 2, pp. 285-307.

https://doi.org/10.4185/RLCS-2019-1331 
Mateos-Pérez, Javier (2021). “La investigación sobre series de televisión españolas de ficción. Un estudio de revisión crítica (1998-2020)". Revista mediterránea de comunicación, v. 12, n. 1, pp. 171-190. https://doi.org/10.14198/MEDCOM000016

Mezzera, Pina (2019). “Informe: España estrenará más de 70 series originales en 2020”. TTV News, 9 diciembre. https://todotvnews.com/informe-espana-estrenara-mas-de-70-series-originales-en-2020

Muñoz-Fernández, Horacio (2016). “¿Son arte las series de televisión?”. Index.comunicación, v. 6, n. 2, pp. 69-82. https://journals.sfu.ca/indexcomunicacion/index.php/indexcomunicacion/article/view/230

Obitel (2011-2020). Anuarios Obitel. Observatorio Iberoamericano de la Ficción Televisiva. http://www.obitel.net

Palenzuela-Zanca, Julia; Marcos-Ramos, María; González-de-Garay, Beatriz (2019). “Representación de la diversidad funcional en series contemporáneas españolas de prime time”. Index.comunicación, v. 9, n. 3, pp. 165-183. https://doi.org/10.33732/ixc/09/03Repres

PwC (2018). La oportunidad de los contenidos de ficción en España: Análisis de oportunidad. https://www.pwc.es/es/entretenimiento-medios.html

Ryan, Maureen; Littleton, Cynthia (2017). "TV series budgets hit the breaking point as costs skyrocket in peak TV era". Variety, 26 Sept.

https://variety.com/2017/tv/news/tv-series-budgets-costs-rising-peak-tv-1202570158

Tamayo-y-Tamayo, Mario (1984). El proceso de la investigación científica. México: Editorial Limusa. ISBN: 9681858727

Torrado-Morales, Susana; Castelo-Blasco, Carmen (2005). “Series de ficción de producción nacional y telespectadores: un negocio en bandeja". Comunicar, v. 25, n. 3.

https://www.redalyc.org/articulo.oa?id=15825097

Tous-Rovirosa, Anna (2019). “El género policiaco en la ficción española (1990-2010): el auge de las cadenas privadas y los valores conservadores". Journal of Spanish cultural studies, v. 20, pp. 483-503.

https://doi.org/10.1080/14636204.2019.1689705

Tous-Rovirosa, Anna; Hidalgo-Marí, Tatiana; Morales-Morante, Luis-Fernando (2020). "Serialización de la ficción televisiva: el género policiaco español y la narrativa compleja. Cadenas generalistas (1990-2010)". Palabra clave, v. 23, n. 4, e2342.

https://doi.org/10.5294/pacla.2020.23.4.2

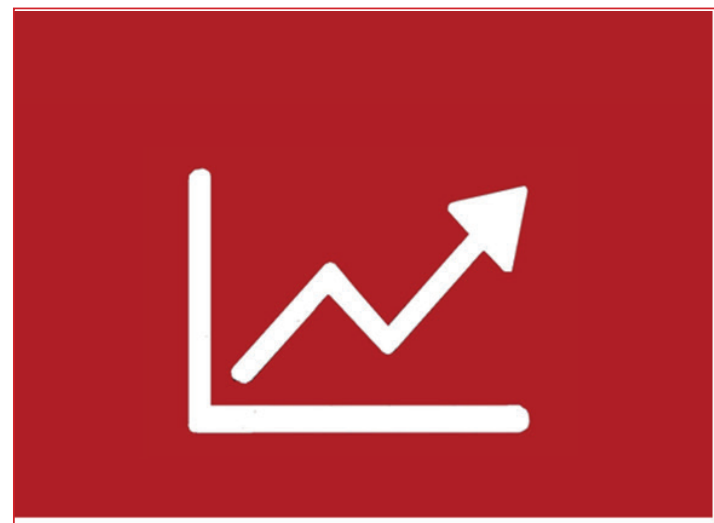

O Dialnet | métricas
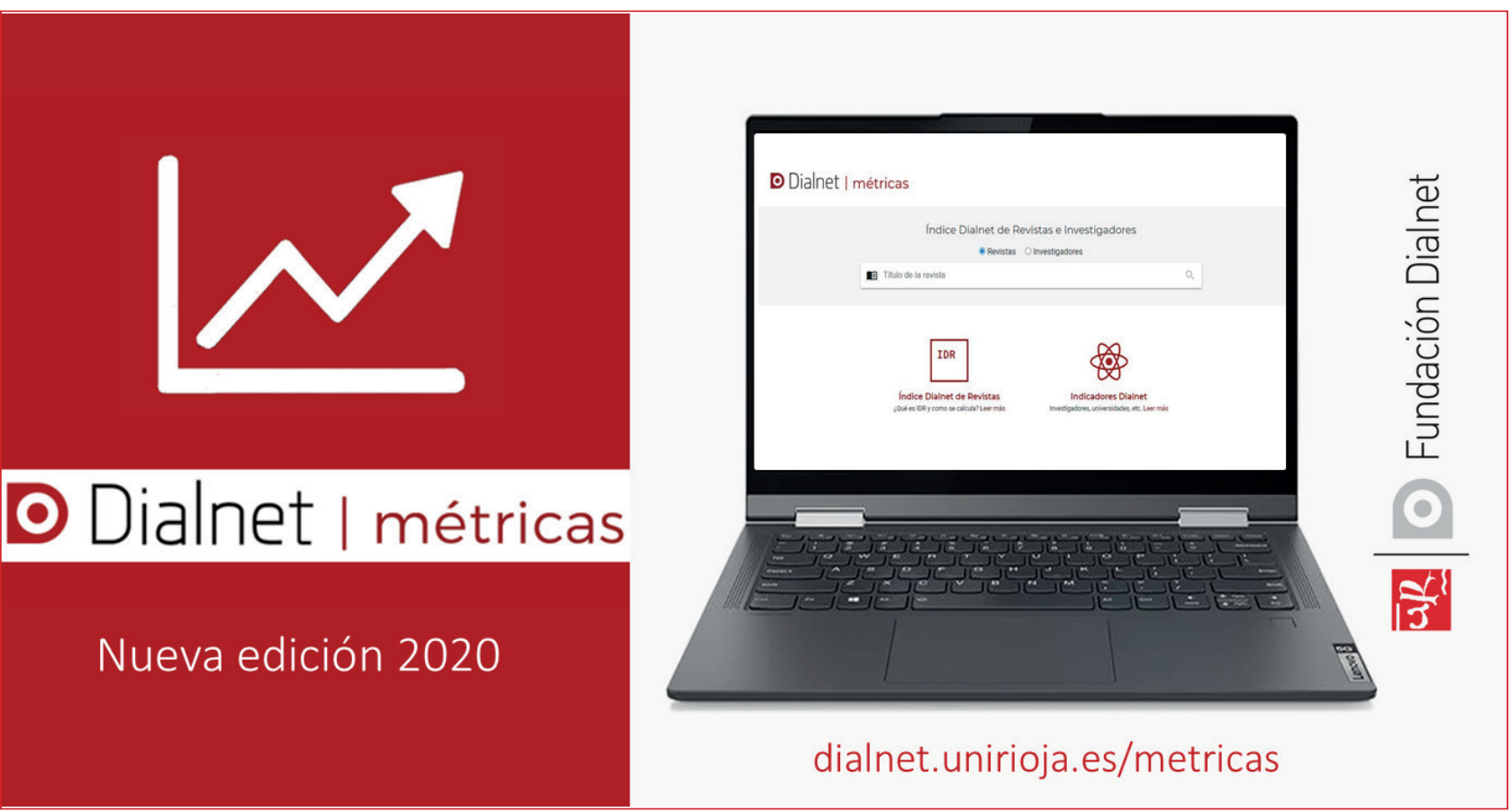